\title{
THE COURSE OF THE VOLUME FRACTION OF MARTENSITE VS. TEMPERATURE FUNCTION Mx(T)
}

\author{
B. SKROTZKI \\ Institut für Werkstoffe, Ruhr-Universität Bochum, Postfach 1021 48, D-4630 Bochum 1, Germany
}

\begin{abstract}
Next to the starting temperatures the course of the martensite formation is of special interest. It can be smooth, step-wise or burst--like. This depends on the alloy system, the defect structure including grain size of the austenite and on the morphology of the martensitic microstructure, i. e. on its nucleation and growth.

Investigations on the transformation course of f.c.c. Fe- $\mathrm{Ni}-$ base, $\mathrm{Fe}-\mathrm{Mn}$ and $\mathrm{Fe}-\mathrm{Cr}-\mathrm{C}$ alloys were compared with b.c.c. shape memory alloys.

In burst-like transformation no continuous function volume fraction of martensite vs. temperature $f_{\alpha}(T)$ can be observed. To describe some microstructures, fractal analysis is applied, because conventional methods of quantitative metallography fail. With these investigations of the transformation course it is expected to get a better understanding of the martensitic transformation itself. Attemps are made for an analytical description of the $f_{\alpha}(T)$-function, based on experimental and theoretical analysis.
\end{abstract}

\section{Introduction}

Whereas a lot of intensive investigation was made on the martensite start temperature and on the variables which influence $\mathbf{M}_{\mathbf{s}}$, less attention has been payed to the transformation course. In principle three different types of athermal transformation can be distinguished: smooth, stepwise or burst (fig. 1). In the case of $\mathrm{Fe}-\mathrm{Mn}$-base alloys the transformation never becomes complete (curve $\mathrm{d}$ in fig. 1), no matter how much the temperature is reduced below $\mathrm{M}_{\mathrm{s}}$. The transformation curves of $\mathrm{Fe}-\mathrm{Ni}$ and $\mathrm{Fe}-\mathrm{Ni}-\mathrm{C}$ alloys with $\mathrm{M}_{\mathrm{s}}<0{ }^{\circ} \mathrm{C}$ show the burst phenomenon. The transformation abruptly starts at $\mathrm{M}_{\mathrm{b}}$ and a quantity of martensite is formed in a single event. Values of $70 \%$ martensite with a temperature increase of $30^{\circ} \mathrm{C}$ are reported $/ 1 /$.

It is well known that the transformation begins at the martensite start temperature $\mathrm{M}_{\mathbf{s}}$ which is determined by the temperature of the metastable thermodynamical equilibrium $\mathbf{T}_{0}$ and the necessary undercooling $\Delta \mathrm{T}$ :

$$
\mathrm{M}_{\mathrm{s}}=\mathrm{T}_{0}-\Delta \mathrm{T} .
$$

The transformation only proceeds if further undercooling is available. It is assumed that the volume fraction of austenite transformed is only a function of temperature $T$ if stabilization effects are excluded. Some empirical formulae are already available but their validity is restricted to carbon and low alloy steels $/ 2,3 /$. The martensite transformation curves of many steels are of similar shape /4/. All curves show a linear region between about 5 and $55 \%$, which can be described with empirical formulae mentioned above.

In this work the transformation courses of fcc $\mathrm{Fe}-\mathrm{Ni}$-base, $\mathrm{Fe}-\mathrm{Mn}, \mathrm{Fe}-\mathrm{Cr}-\mathrm{C}$ alloys are compared with bcc NiTi and $\mathrm{CuAlNi}$ shape memory alloys. Based on experimental and analytical work attemps are made for a quantitative description of the function $\mathrm{f}_{\alpha}(\mathrm{T})$. In addition, fractal analysis is applied to some microstructures where classical quantitative metallography fails. 


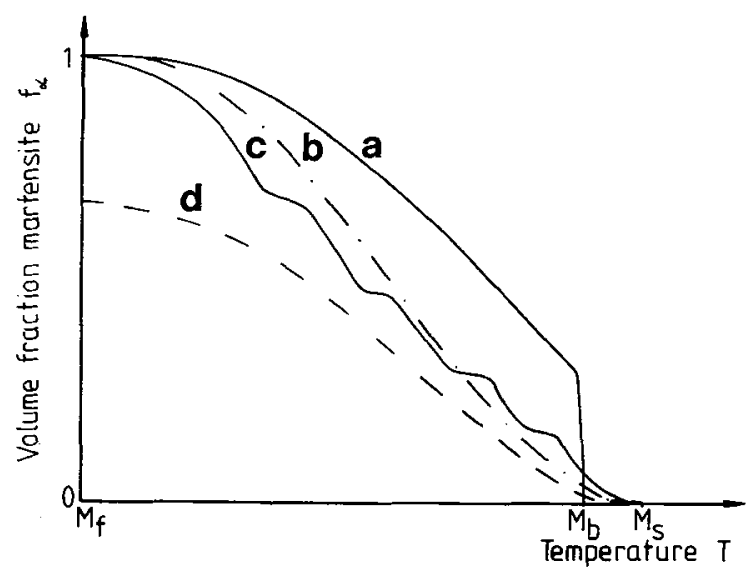

Fig. 1: Different types of transformation courses (schematic)

\section{Experimental procedure}

The composition of the investigated alloys is listed in table 1. The last three are shape memory alloys (SMA).

Table 1: Chemical composition of the alloys investigated

\begin{tabular}{ll} 
Alloy & composition in wt.\% \\
\hline FeNi & Fe-30.8Ni \\
FeMn & Fe-24.5 Mn \\
FeCrC & Fe-1.01Cr-0.64C \\
FeNiCoTiAl & Fe-30.1 Ni-10.4Co-3.1Ti-2.3Al \\
CuAlNi & $\mathrm{Cu}-12.7 \mathrm{Al}-4.11 \mathrm{Ni}$ \\
NiTi & $\mathrm{Ni}-44.2 \mathrm{Ti}$
\end{tabular}

The transformation temperatures were determined with calorimetric (DSC) and dilatometric measurements (cooling rate $1^{\circ} \mathrm{C} / \mathrm{min}$ ). The transformation course is obtained from these data. In the case of DSC plots the transformed volume fraction results from

$$
\mathrm{f}_{\alpha}=\frac{\Delta \mathrm{H}}{\Delta \mathrm{H}_{\mathrm{t}}} \text {. }
$$

$\Delta \mathrm{H}$ is the transformation enthalpy for an appointed temperature between $\mathrm{M}_{\mathrm{s}}$ and $\mathrm{M}_{\mathrm{f}}$ and $\Delta \mathrm{H}_{\mathrm{t}}$ is the total transformation enthalpy. Out of dilatometer plots $\mathrm{f}_{\alpha}$ is obtained from the volume and length change, respectively

$$
\mathrm{f}_{\alpha}=\frac{1_{0}-1}{1_{0}-1_{1}} \text {. }
$$

$\mathrm{l}_{0}$ means the length prior to the beginning of the transformation, $l_{1}$ the length after the transformation is finished and 1 is the length between $M_{S}$ and $M_{f}$. If the transformation was incomplete the actual fraction of martensite was determined semi quantitatively by an image analyser. The calculated values were then related to the actual values.

\section{Results and discussion}

Fig. 2 shows the transformation course of the Fe-Ni alloy with burst martensite. At $\mathrm{M}_{\mathrm{b}}=-31^{\circ} \mathrm{C}$ a volume fraction of about $30 \%$ is formed with a temperature increase of about $10^{\circ} \mathrm{C}$ due to the sudden release of the heat of transformation. In this case it is impossible to give a continuous description of the curve. To proceed the transformation, additional undercooling of several degree $\mathrm{C}$ below $M_{b}$ is necessary. This is due to a stabilization effect as a result of the warming of the 


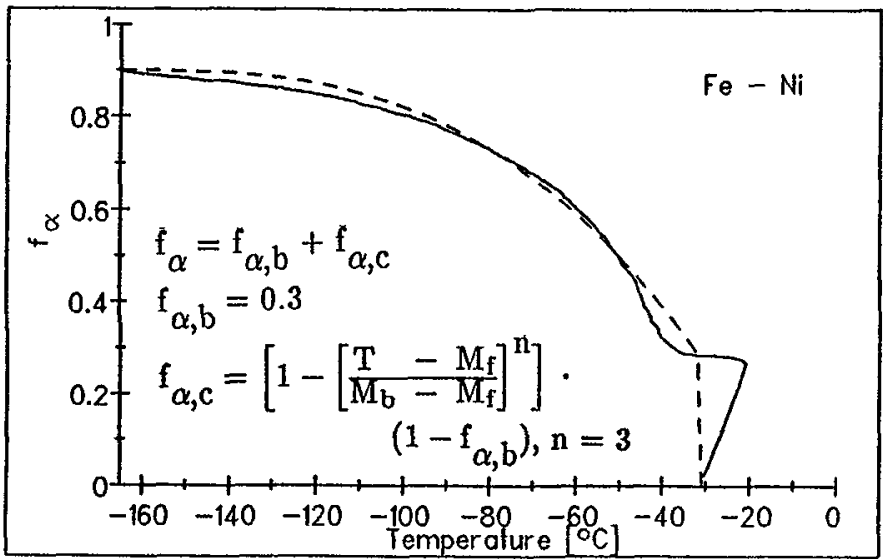

Fig. 2: Burst transformation in an $\mathrm{Fe}-30.8 \mathrm{Ni}$ alloy (dilatometry); broken line: calculated volume fraction.

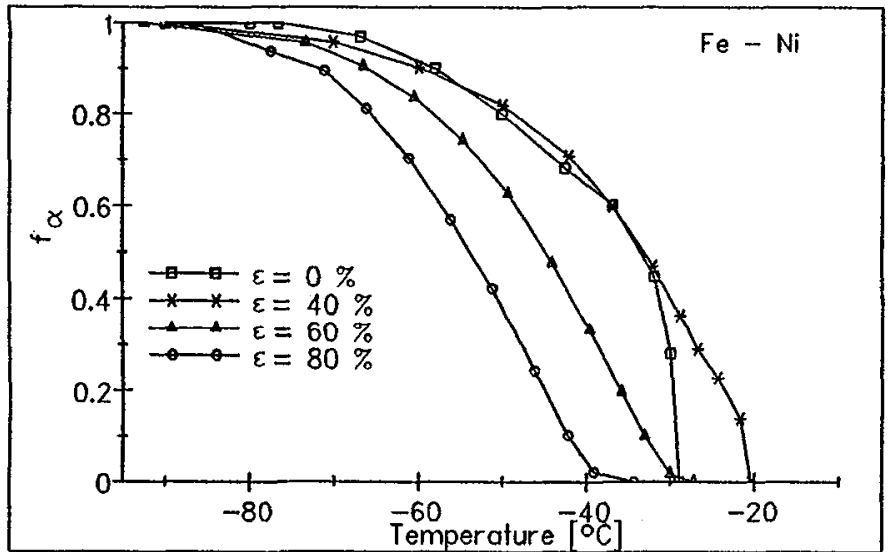

Fig. 3: Transformation course after plastic deformation of the austenite (DSC).

specimen.

The course of the burst transformation is changed if the specimen is plastically deformed e.g. by cold rolling. Fig. 3 illustrates the results for different degrees of deformation $\epsilon$. Without deformation the abrupt transformation is followed by a continuous smooth course. At $40 \%$ deformation the curve is less steep in the beginning. $M_{S}$ is raised as a result of the increasing number of nucleation sites. Further deformation lowers $\mathrm{M}_{\mathrm{s}}$ because of the increasing yield strength and inhomogeneous slip distribution. At 60 and $80 \%$ deformation the course is changed to the smooth type. This is due to the introduced slip bands which appear at $\varepsilon>30 \%$. In an undeformed specimen the martensite crystall can move through the whole austenite grain and a large volume fraction can transform. The slip bands act as impediments (see micrograph in fig. 3 ). The martensite crystalls are limited in their growth and therefore a smaller amount transforms until the shape becomes very smooth.

In the Fe-Mn system with more than $15 \% \mathrm{Mn}$ the hexagonal $\epsilon$ martensite is formed. In contrast to $\alpha$ martensite the $\gamma-\epsilon$ transformation is associated with a volume contraction of about $1.5 \%$. A considerable amount of retained austenite remains because of the absence of invariant strain and a stabilization of the austenite due to the antiferromagnetic transition. Therefore the course of the $\mathrm{Fe}-\mathrm{Mn}$ alloy has a different shape. The curve in fig. 4 slowly ascends and the martensite fraction attains only about $45 \%$.

On the other hand the $\mathrm{Fe}-\mathrm{Cr}-\mathrm{C}$ steel transforms nearly completely. The curve in fig. 5 shows a steep increase but no burst phenomenon. Between 5 and $60 \%$ transformed martensite a quite linear range can be observed. This is in accordance with results reported in the literature $/ 3,4 /$. 


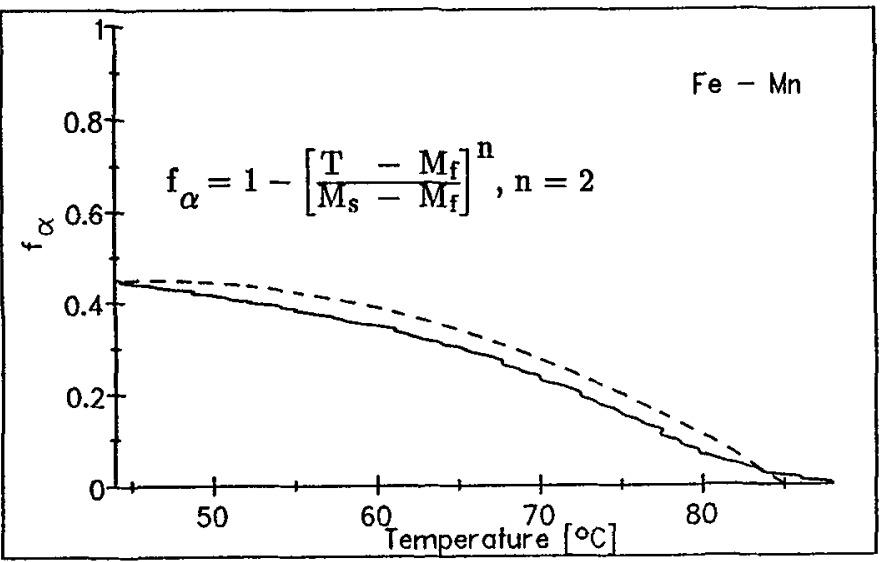

Fig. 4: Incomplete transformation of an $\mathrm{Fe}-\mathrm{Mn}$ alloy with hcp $\epsilon$-martensite (dilatometry).

The curve of the Fe-base shape memory alloy shows an increasing course of the transformed volume fraction which is clearly less steep (fig. 6). All other investigated alloys show a steep increase in the middle part of the curve. The martensite in this alloy is thermoelastic because small ordered and coherent $\gamma^{\prime}$ particles are sheared in a metastable structure through the transformation. This possibly gives rise to the unusual transformation course.

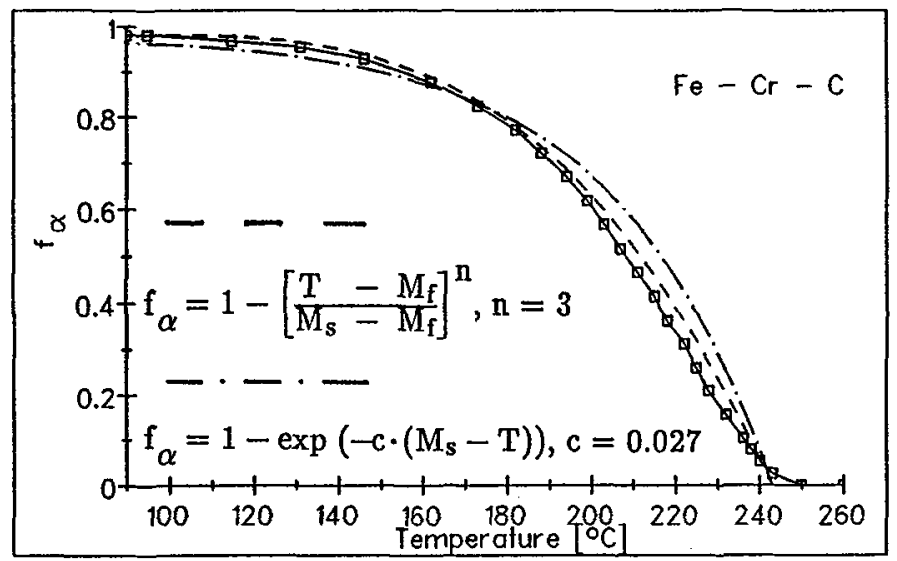

Fig. 5: Transformation course of an $\mathrm{Fe}-\mathrm{Cr}-\mathrm{C}$ steel (dilatometry).

The investigated bcc shape memory alloys NiTi and CuAlNi both have a smooth course (fig. 7 and 8). The NiTi alloy has a linear range between 10 and $60 \%$ martensite transformed. The temperature range $\mathrm{M}_{\mathrm{S}}-\mathrm{M}_{\mathrm{f}}$ is clearly smaller than in the $\mathrm{Fe}$-base alloys. The transformation is thermoelastic, austenite and martensite are ordered and the martensite phase forms in a self-accomodating manner. Elastic energy of the austenite-martensite transformation is stored and therefore the temperature hysteresis is small.

In the literature some attemps are reported to find a quantitative description of the transformation course $/ 2,3,5,6 /$. The formula with the best fitting for all alloys is

$$
\mathrm{f}_{\alpha}=1-\left[\frac{\mathrm{T}-\mathrm{M}_{\mathrm{f}}}{\mathrm{M}_{\mathrm{s}}-\mathrm{M}_{\mathrm{f}}}\right]^{\mathrm{n}}
$$

The calculated results are illustrated in fig. 2, 4, 5, 7, 8 as broken lines. The exponent $\mathrm{n}$ is between 2 and 3 , depending on the alloy system. For $\mathrm{Fe}-\mathrm{Mn}$ the curve does not show a good correspondence as $\gamma-\epsilon$ transformation is kinetically different. For the Fe-Ni-base SMA the proposed formula is not suitable. In the case of burst martensite in the $\mathrm{Fe}-\mathrm{Ni}$ alloy it is proposed to subdivide the formula in one part for the fraction formed by burst and another part formed by continuous 


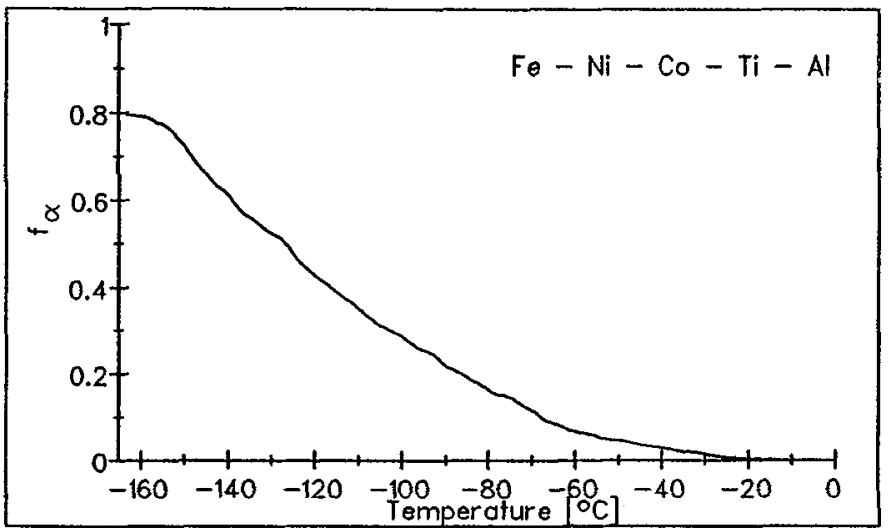

Fig. 6: Transformation course in an $\mathrm{Fe}-\mathrm{Ni}-\mathrm{Co}-\mathrm{Ti}-\mathrm{Al}$ shape memory alloy (dilatometry).

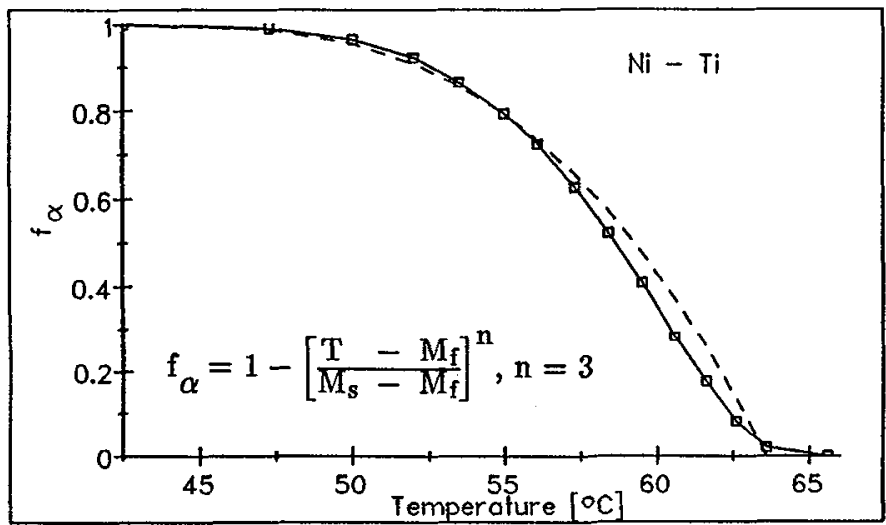

Fig. 7: Smooth course of an $\mathrm{Ni}$ - Ti shape memory alloy (DSC).

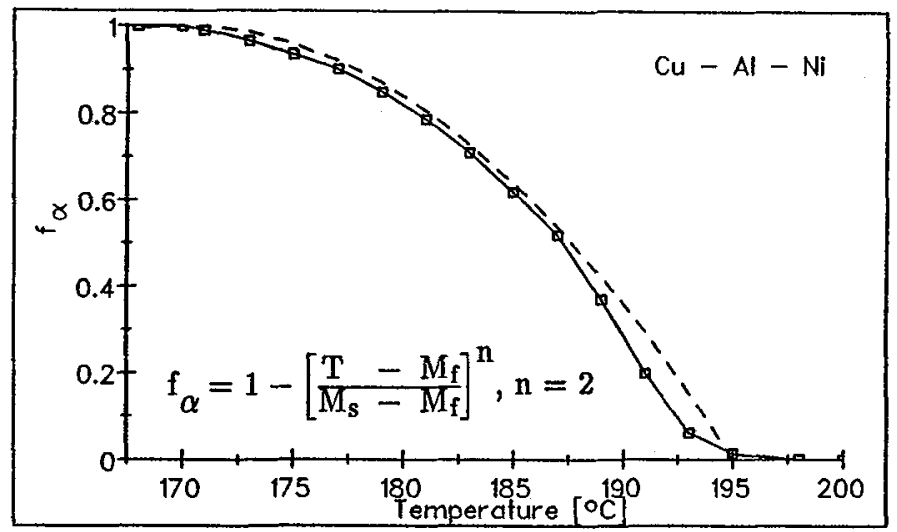

Fig 8: Smooth transformation course of a $\mathrm{Cu}-\mathrm{Al}-\mathrm{Ni}$ shape memory alloy (DSC). 
transformation:

$$
\mathrm{f}_{\alpha}=\mathrm{f}_{\alpha, \mathrm{b}}+\mathrm{f}_{\alpha, \mathrm{c}}
$$

For the $\mathrm{Fe}-\mathrm{Cr}-\mathrm{C}$ alloy a slightiy modified formula of /3/ also shows a good correspondence. This is reasonable because it was developed for steel specimens.

It is assumed that the burst size increases with decreasing $\mathrm{M}_{\mathrm{b}}$. Other authors $/ 7 /$ suggest that burst is a general characteristic of martensite formation. The growth takes place discontinuously, each step of rapid growth being followed by a much longer time interval during which little or no transformation takes place. In the individual bursts a very small amount of martensite is formed. This should lead to a stepwise transformation (see fig. 1) which is reported to take place in Ni-Ti alloys at slow cooling rates $/ 8 /$.

Martensite belongs to disordered microstructures which cannot be described by classical quantitative metallography. In this case fractal analysis is proposed $/ 9,10 /$. In $\mathrm{Fe}$-base alloys with lenticular martensite several generations of martensite crystals can be distinguished. In bcc SMA separation of individual steps of fragmentation of an austenite grain is also possible /8/. For fractal analysis self-similarity of the microstructure is required. The results of a fractal analysis of an $\mathrm{Fe}-\mathrm{Ni}$ alloy are illustrated in fig. 9. The plot shows the size and distribution function of different maItensite generations. A similar analysis is possible for the size and distribution of the retained austenite.
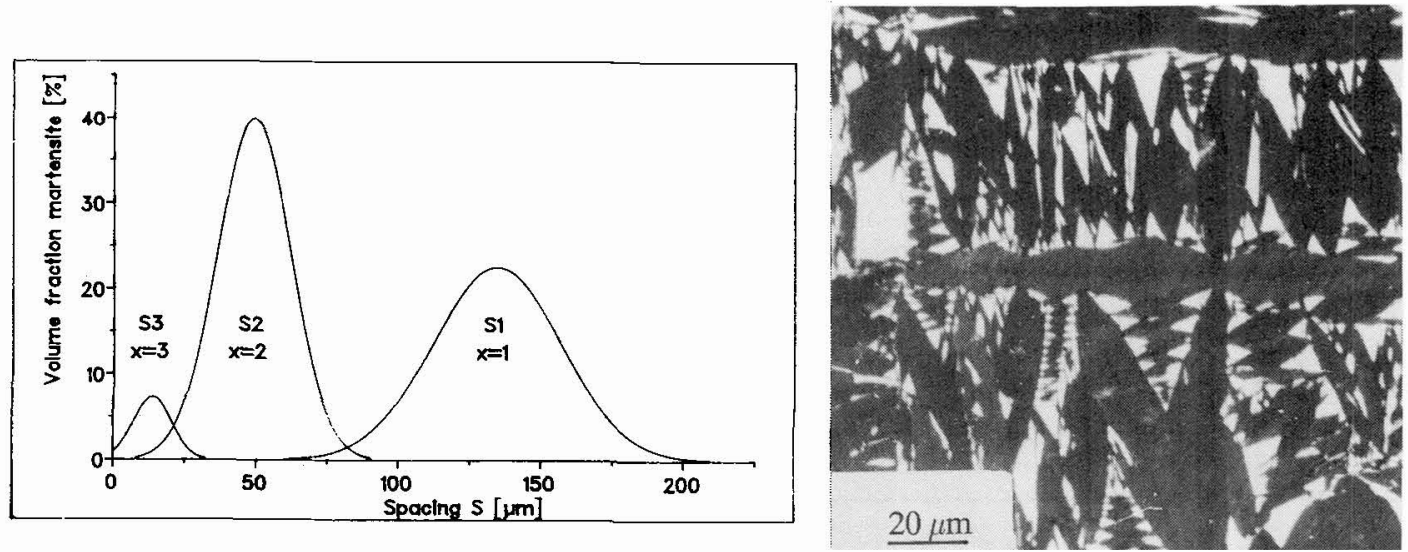

Fig. 9: a) Distribution function of different martensite crystal generation in Fe-30.25 Ni.

b) Microstructure of fractal lenticular martensite.

\section{Acknowledgement}

This work was supported by the Volkswagen Foundation (Project COSMOS I/63846). Thanks are due to $\mathrm{P}$. Donner and $\mathrm{N}$. Jost who provided the $\mathrm{Ni}-\mathrm{Ti}, \mathrm{Cu}-\mathrm{Al}-\mathrm{Ni}$ and $\mathrm{Fe}-\mathrm{Ni}-\mathrm{Co}-\mathrm{Ti}-\mathrm{Al}$ alloys, respectively.

\section{References}

/1/ Entwisle, A.R., Met. Trans. 2 (1971) 2395

/2/ Harris, W.J., Cohen, M., Trans. AIME 180 (1949) 447

/3/ Koistinen, D.P., Marburger, R.E., Acta Met. 7 (1959) 59

14) Brook, R., Entwisle, A.R., Ibrahim, E.F., J. Iron Steel Inst. 195 (1960) 292

15/ Wildau, M., Hougardy, H.P., Proceedings of the International Conference on the Residual Stresses, Garmisch-Partenkirchen (1986) 573 (formula based on private communications)

/6/ Wildau, M., Hougardy, H.P., see /5/

17/ Wasilewski, R.J., Met. Trans. 6A (1975) 1405

18/ Jiang, Q., Lück, R., Predel B., in "The Martensitic Transformation in Science and Technology", Hornbogen, E., Jost, N. (ed.), Bochum (1989) 179

/9/ Hornbogen, E., Int. Mat. Rev. 34 (1989) 277

/10/ Skrotzki, B., J. Mat. Sci. 26 (1991) 1073 